\title{
É POSSÍVEL UTILIZAR FONTES HISTÓRICAS NAS AULAS DE MATEMÁTICA DA EDUCAÇÃo BÁSICA?
}

\section{IS IT POSSIBLE TO USE HISTORICAL SOURCES IN BASIC EDUCATION MATHEMATICS CLASSES?}

\author{
Daniele Esteves Pereira ${ }^{1}$ \\ Universidade Federal do Pará
}

\begin{abstract}
Resumo
O ensino e aprendizagem de matemática em todos os segmentos da Educação Básica tornou-se pauta das principais discussões acerca da qualidade do ensino deste segmento em nosso país. A preocupação com o ensino da disciplina também tem fomentado o desenvolvimento de pesquisas no campo da Educação Matemática. Uma das perspectivas desses estudos aponta para a inserção da História da Matemática como um recurso metodológico nas salas de aula que combatem um ensino estritamente dedutivoformal. Este artigo mostra de forma bastante clara possibilidades plausíveis de utilização de fontes históricas no ensino de Matemática por meio da exploração didática da Lettres à une Princesse d'Allemagne sur divers sujets de physique et de philosophie de Leonhard Euler escrita sob a forma de cartas pedagógicas no século XVIII. Nesse caso, buscou-se fundamentar a constituição histórica de conceitos matemáticos e suas relações com o desenvolvimento da ciência, juntamente com uma abordagem pedagógica que favoreça a desmistificação de tabus solidamente estabelecidos de que a matemática tem um fim em si mesma é difícil de aprender.
\end{abstract}

Palavras-Chave: História da Matemática; Ensino de Matemática; Educação Básica.

\begin{abstract}
The teaching and learning of mathematics in all segments of Basic Education has become the main discussion about the quality of teaching in this segment in our country. The concern with the teaching of the discipline has also fostered the development of research in the field of Mathematics Education. One of the perspectives of these studies points to the insertion of the History of Mathematics as a methodological resource in classrooms that combat a strictly formal-deductive teaching. This article shows in a very clear way plausible possibilities of using historical sources in the teaching of Mathematics through the didactic exploration of Lettres à une Princesse d'Allemagne sur divers sujets de physique et de philosophie de Leonhard Euler written in the form of pedagogical letters in the XVIII century. In this case, we sought to base the historical constitution of mathematical concepts and their relations with the development of science, together with a pedagogical approach that favors the demystification of solidly established taboos that mathematics has an end in itself is difficult to learn.
\end{abstract}

Keyword: History of Mathematics; Teaching of Mathematics; Basic Education.

\footnotetext{
1'desteves@ufpa.br.
} 


\section{Introdução}

A pesquisa sobre formação de professores é a mola propulsora de muitos trabalhos sobre as dificuldades relativas à aprendizagem em Matemática. Partindo de situações reais vivenciadas como professora da Educação Básica, fomos em busca de aportes didático-metodológicos que nos permitissem investigar quais as potencialidades didáticas de atividades planejadas para o ensino de ciências e matemática a partir de obras históricas originais, ou seja em fontes primárias. Neste caso específico, tomamos a produção literária que se tornou sucesso na Europa, escrita em forma de cartas por Leonhard Euler na segunda metade do século XVIII, intitulada - Lettres à une Princesse d'Allemagne sur divers sujets de physique et de philosophie (Cartas a uma princesa da Alemanha sobre diversos temas de física e de filosofia).

Apresentamos a obra de Euler, enfatizando o conteúdo matemático identificado, tecemos observações sobre o contexto sociocultural da época em que as Lettres à une Princesse d'Allemagne foram escritas, assinalamos aspectos considerados relevantes para o exercício da docência em matemática na Educação Básica e, finalmente abordamos aspectos e possibilidades concretas de transposições didáticas ${ }^{2}$ com o uso desse material em nossas salas de aulas de matemática da atualidade, sejam da Educação Básica ou até mesmo em cursos de professores em formação.

A rede de contextos que entrelaçamos na escrita do texto tem o propósito de discutir o potencial pedagógico existentes em Lettres à une Princesse d'Allemagne, a partir dos princípios teóricos do uso da História da Matemática em sala de aula e na transposição didática de conteúdos matemáticos oriundos de fontes históricas para o contexto escolar.

É fato explícito que as Lettres à une Princesse d'Allemagne foram escritas com finalidade de ensinar diversos tópicos de áreas distintas do conhecimento a jovem

\footnotetext{
${ }^{2}$ As ideias de Transposição Didática utilizadas nesta pesquisa foram alimentadas inicialmente pela teoria original formulada pelo sociólogo Michel Verret, em 1975. Entretanto em 1980, o matemático Yves Chevallard retoma essa ideia e a insere num contexto mais específico, fazendo dela uma teoria e com isso analisando questões importantes no domínio da Didática da Matemática. Em seu trabalho, CHEVALLARD (1991) analisou como o conceito de "distância" nasce no campo da pesquisa em matemática pura e reaparece modificado no contexto do ensino de Matemática. Ele define a Transposição Didática como um recurso eficiente de análise do processo por meio do qual o saber produzido pelos cientistas (Saber Sabedor) se transforma naquele que está contido nas orientações curriculares, conteúdos programáticos e livros didáticos (o Saber a Ensinar) e, potencialmente, naquele que efetivamente aparece nas salas de aula (o Saber Ensinado). CHEVALLARD analisa as modificações que o saber produzido pelos "sábios" (cientistas) sofre até este ser reformulado em um objeto de ensino.
} 
monarca alemã. Devido ao reconhecimento de seu grande potencial pedagógico foi amplamente utilizada na instrução intelectual da juventude europeia do século XVIII.

Dessa forma, os conteúdos matemáticos, e as possibilidades de uso didáticos nas aulas de matemática advindos das Cartas de Euler a princesa alemã foram tratados sobretudo nas cercanias delimitadas pelo campo das teorias sobre o uso da História da Matemática em sala de aula.

\section{Fontes históricas como recurso didático para o ensino de matemática}

As informações matemáticas inseridas no texto de Euler escrito há quase 300 anos com finalidades didáticas precisam ser revitalizadas por ponderações sobre quando, como e onde a utilização da História da Matemática pode auxiliar no emprego de metodologias de ensino desta disciplina ao fazer uso de textos históricos. Jahnke et al (2000, livre tradução) defende que "Se o valor da história reside na reorientação, em vez da compreensão, logo, os textos precisam ser contextualizados, e situados aos cenários do tempo atual. Precisamos nos lembrar de que o escritor não estava se dirigindo a nós, mas um público contemporâneo a sua época."

Esta assessoria da História da matemática é importante para atribuir um frescor indispensável aos textos históricos, afim de que estejam aptos a serem aplicados nas classes de matemática de forma interessante, motivadora, questionadora e principalmente, ao que considero mais importante para os objetivos desta pesquisa é que possibilitem o exercício da transversalidade entre a matemática com outras disciplinas ou com outras áreas do conhecimento como a ética, o meio ambiente e a pluralidade cultural tão bem recomendadas pelos PCN de matemática.

\footnotetext{
Nas várias áreas do currículo escolar existem, implícita ou explicitamente, ensinamentos a respeito dos temas transversais, isto é, todas educam em relação a questões sociais por meio de suas concepções e dos valores que veiculam nos conteúdos, no que elegem como critério de avaliação, na metodologia de trabalho que adotam, nas situações didáticas que propõem aos alunos. Por outro lado, sua complexidade faz com que nenhumas das áreas, isoladamente, seja suficiente para explica-los; ao contrário, a problemática dos temas transversais atravessa os diferentes campos do conhecimento (BRASIL, 1998, p. 26)
}

Não se pode utilizar a articulação entre História e o ensino de Matemática sob bandeira da contextualização artificial muito defendida nos livros didáticos, que usam as fontes históricas como "áreas de garimpo", utilizáveis para a extração de informações numéricas a serem aproveitadas nas resoluções de problemas e operações matemáticas. 
Estas conexões se fazem presentes e necessárias pelo fato de que a construção de novos significados e a ampliação de ferramentas cognitivas só podem ser vistas a partir do enlace de saberes diversificados capazes de promover analogias, diálogos, relações, convergências e divergências entre as disciplinas.

A todos estes movimentos reflexivos oriundos do exercício de articulação da Matemática e outras disciplinas, via História da matemática repousam os créditos da concretização de metodologias de ensino que possibilitem aos professores e alunos a pensar sobre a matemática, não apenas como parte do currículo ou como uma tarefa escolar, mas como resultado de uma atividade humana inserida em um processo social e histórico.

Nossas proposições encontram eco e propagam seu som nas palavras de Tomaz e David (2013, p. 9) quando revelam que a opção por uma prática escolar deve ser feita de modo que estejam assegurados prioritariamente a aprendizagem matemática dos alunos em qualquer situação adotada, antes mesmo da defesa de sua teoria específica. Esclarecem ainda que a partir desse posicionamento adotado, as propostas eleitas devem ser as que possibilitem a "associação entre as aprendizagens e a participação nas práticas escolares respaldadas em perspectivas histórico-culturais."

Tomaz e David (2013, p. 10) seguem ratificando que "as práticas e aprendizagens matemáticas não se encerram nem se limitam ao espaço específico da disciplina escolar Matemática”, permitindo a abertura para que outras disciplinas e práticas escolares tenham espaço para serem debatidas. Assim, mais uma vez encontro reverberação dos posicionamentos indicados na pesquisa, os quais investem na aproximação do ensino de matemática à concepções de práticas escolares que adotam a transversalidade como um vetor para a compreensão do conhecimento matemático como decorrência de uma construção humana, inserida em um processo social, cultural e histórico. (MENDES, 2006)

Como bem lembra (JAHNKE et al, 2000, livre tradução) a utilização de fontes históricas originais nas aulas de matemática é um projeto ambicioso, porém proporcionalmente gratificante. Sua ousadia refere-se a dois fatos: Primeiramente, para que uma fonte histórica original seja usada didaticamente nas aulas de matemática é necessário haver uma compreensão detalhada e profunda do momento em que ela foi escrita e do contexto geral das ideias; segundo, e não menos importante está nas formas 
de linguagem empregadas que são inteiramente novas em comparação com as práticas usuais de ensino da matemática.

Daí consiste o aspecto que enfatizamos de que um texto histórico original precisa receber um tratamento, ou seja, necessita passar por uma transposição didática, a fim de que esteja adequado à realidade de nossas salas de aula. A mesma ressalva é dividida com (JAHNKE et al, 2000, p. 293, tradução livre) quando preocupa-se com o fato de que "A incorporação de fontes primárias em si não boa ou ruim. Precisamos estabelecer objetivos, incluindo população-alvo, o tipo de fonte que pode ser adequada e a metodologia didática necessária para suportar a sua constituição”.

A lista de argumentos favoráveis ao seu uso das fontes originais é significativamente numerosa e variada. Passam por pontos que defendem a ampliação e esclarecimentos acerca do que é encontrado em materiais secundários, a liberdade de interpretação sem interferências de leituras precedentes, até a possibilidade de visualizar outras tendências da História da matemática que rompem as barreiras cronológicas. (JAHNKE et al, tradução livre)

Porém é necessário ponderar imparcialmente o ensino de Matemática atual e elencar as dificuldades de aprendizagem e limitações de conhecimentos que ainda persistem. Uma destas é a dificuldade na leitura e compreensão destes textos pelos alunos. Outra seria a formação adequada para os professores. Estes precisariam estar imbuídos do propósito do senso histórico para poderem fazer a releitura dos textos históricos com a finalidade direcionada para o uso em sala de aula. É elementar que as informações matemáticas encontradas sejam ressaltadas e transformadas em recursos auxiliares nas aulas de matemática.

A seguir, exemplificamos algumas possibilidades de utilização de fontes históricas por meio da intervenção na obra Lettres à une Princesse d'Allemagne de Leonhard Euler. A obra foi selecionada e analisada, conforme critérios explanados anteriormente. Apresentamos as fontes, pontuando o conteúdo matemático identificado, tecendo observações sobre o contexto sociocultural da época em que as obras foram escritas, assinalando aspectos considerados relevantes para o exercício da docência em matemática na educação básica. Indicando possibilidades concretas do uso desse material em aulas de matemática atualmente, sejam da Educação Básica ou até mesmo em cursos de professores em formação. 
Lettres à une Princesse d'Allemagne sur divers sujets de physique et de philosophie como recurso didático nas aulas de matemática

A produção literária de Leonhard Euler que se tornou sucesso na Europa, escrita em forma de cartas na segunda metade do século XVIII, é traduzida como as Cartas a uma princesa da Alemanha sobre diversos temas de física e de filosofia, foi a fonte histórica utilizada para ser nosso objeto de investigação das potencialidades didáticas de atividades planejadas para o ensino de ciências e matemática a partir de obras históricas originais, ou seja, em fontes primárias.

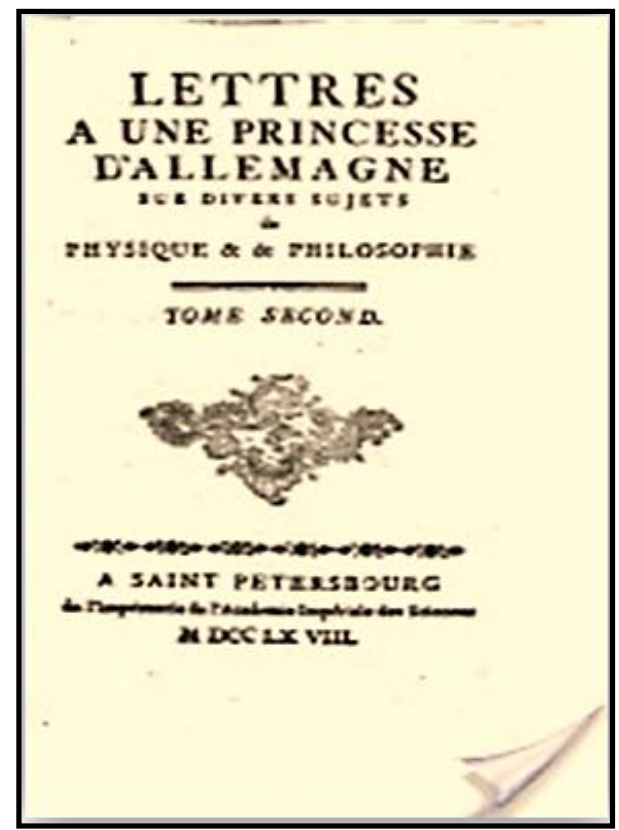

Imagem 0: Capa do segundo tomo de Lettres à une Princesse d'Allemagne sur divers sujets de physique et de philosophie.Fonte: FELMANN, 2007.

A obra consiste em uma coletânea de mais de 200 cartas cartas que foram escritas na língua francesa no período compreendido entre 1760 a 1762 depois que Euler foi convidado pelo rei da Prússia Frederico II, o Grande (1712-1786), para residir em Berlim onde acabara por tornar-se tutor da sobrinha do monarca, episódio que o levou a escrever as epistolas com o intuito de ensinar conteúdos sobre as mais diversos temas como matemática, astronomia, filosofia, entre outros, tomando a correspondência escrita como um recurso didático apropriado para o seu exercício de ensino e formação intelectual (cultura geral sobre filosofia e ciência) de duas jovens, a Princesa AnhaltDessau (1745-1808), Margravina Sophie Charlotte Frederike Leopoldina von 
Brandenburg-Schwedt e, sua irmã, Louise, em nome de seu pai. (PEREIRA, 2014, p. 13).

A escolha de tutores para conduzir a educação intelectual da realeza alemã e de outros países europeus era uma prática recorrente no século XVIII, devendo ainda essa instrução ser proferida em língua francesa pois, considerava-se ser a França um país ícone em educação e cultura geral.

Estudar em universidades era fato excepcionalmente raro entre o gênero feminino e particpar de comunidades acadêmico-científicas era sumariamente vetado. (BURKE, 2003)

As investigações exploratórias acerca do potencial pedagógico da obra foram realizadas em conformidade com os pressupostos teóricos e metodológicos da História da Matemática, o ensino de Matemática por atividades, o uso de fontes históricas originais como fonte de estudo e, os Parâmetros Curriculares Nacionais de Matemática PCNs.

Nossa análise deteve-se à primeira parte da obra, a qual reúne um conjunto de 79 cartas que versam sobre física, astronomia e teoria musical. Contudo, uma gama de conteúdos de outras áreas do conhecimento encontra-se transversalizados ao longo do conteúdo das demais cartas, como é o caso dos conteúdos matemáticos identificados.

Constatamos que as cartas seguiam uma temática central, que já havia sido confirmada também por Pérez (1990) em sua tradução, o que foi de extrema importância para a identificação de temas e sua classificação por blocos. Assim, os blocos temáticos identificados foram os seguintes:

- Cartas I e II tratam de movimento, velocidade e distância percorrida por um corpo;

- Cartas III a VIII versam sobre teoria musical;

- A partir da Carta IX a temática central é a Física e suas divisões;

- As Cartas de IX a XIII trazem como temática central o ar e suas propriedades;

- Cartas XIV, XV e XVI centralizam seu foco sobre temperatura;

- Cartas de XVII a XLIV abordam a temática acerca da óptica;

- Cartas de XLV a LVIII tecem discussões sobre gravidade dos corpos celestes;

- As Cartas compreendidas entre LIX a LXVIII focam aspectos acerca da sobre astronomia e estão subdivididas em: de LIX a LX sistema do mundo, LXI movimento dos planetas; e LXII a LXVIII marés; 
- A Carta LXVIII trata sobre disputa filosófica em torno da gravitação universal;

- As Cartas LXIX e LXX revelam as propriedades da matéria como extensão, mobilidade e impenetrabilidade;

- As Cartas entre LXXI a LXXV discutem movimento, inércia e forças;

- A Carta LXXIX trata especificamente de força.

A organização das cartas selecionadas ocorreu de acordo com suas temáticas e possível potencial pedagógico, para posteriormente classificá-las segundo os eixos temáticos norteadores dos PCN de matemática, a saber:

1. Números e operações;

2. Espaço e forma;

3. Grandezas e medidas;

4. Tratamento da informação.

Ainda de acordo com os PCN, que pressupõe a conexão dialogal entre a Matemática e os temas transversais, a natureza multidisciplinar dos conteúdos abordados nas cartas aponta para um exercício entre a referida obra de Euler e as orientações didáticas para a matemática escolar, visto que são contemplados de forma conjunta temas como a ética, a filosofia, a física, as ciências naturais, a astronomia entre outros.

Nas várias áreas do currículo escolar existem, implícita ou explicitamente,
ensinamentos a respeito dos temas transversais, isto é, todas educam em
relação a questões sociais por meio de suas concepções e dos valores que
veiculam nos conteúdos, no que elegem como critério de avaliação, na
metodologia de trabalho que adotam, nas situações didáticas que propõem
aos alunos. Por outro lado, sua complexidade faz com que nenhumas das
áreas, isoladamente, seja suficiente para explica-los; ao contrário, a
problemática dos temas transversais atravessa os diferentes campos do
conhecimento (BRASIL, 1998, p. 26).

Utilizamos como exemplo da prática do uso de fontes históricas nas aulas de matemática, o primeiro grupo de correspondências direcionadas à princesa AnhaltDessau que são as cartas I e II que trazem como tema central a mecânica quando discutem distância percorrida, movimento, e velocidade

De acordo com a versão espanhola da obra referência do texto preparada por Pérez (1990)

Iniciam-se as Cartas com algumas considerações gerais sobre a extensão (I) e a velocidade (II). Por meio das quais deve-se constituir uma ideia adequada de quantidade, ressaltando os traços característicos desta: ser mais ou menos 
suscetível, e dispor de parâmetros para determiná-la. Estes parâmetros no caso da velocidade são o espaço percorrido (a extensão) e o tempo utilizado. (PÉREZ, 1990, p. 53).

Pérez (1990) anuncia sutilmente a transversalidade com que Euler aborda seus temas. Os títulos das cartas exercem a função de temas geradores ou fios condutores. Em cada uma delas os conteúdos são abordados de acordo com a temática central, daí são desencadeados tópicos complementares os quais enriquecem tanto a metodologia de ensino utilizada quanto a variedade de conhecimentos levantados. Assim, em uma única correspondência é costurada uma metodologia de ensino transversal, alimentada por assuntos das mais diversas disciplinas.

A forma como Euler apresentava seus conteúdos no longínquo século XVIII é hoje recomendada pelos documentos oficiais a fazerem parte das práticas escolares em substituição de abordagens fragmentadas, como possibilidade de estabelecer o interlocução entre a matemática com outros áreas do conhecimento.

Nas Cartas I e II, o cálculo de distâncias, as unidades de medida de comprimento (pé, polegada e milha), a conversão entre medidas, o seu uso adequado de acordo com a situação utilizada, são conteúdos matemáticos identificáveis no texto que podem estabelecer os canais de diálogos entre outros conteúdos contidos no bloco Grandezas e Medidas dos PCN de matemática e outras áreas do conhecimento.

Um exemplo de utilização dessas primeiras cartas pode ser usada via História da Matemática para buscar explicações no século XVIII, especificamente na Revolução Francesa, para desvendar como as implicações políticas, sociais, econômicas e culturais advindas da ascensão de uma outra classe social no poder respingaram em toda a Europa e, até hoje seus reflexos são perceptíveis no sistema de medidas de comprimento $^{3}$ adotado e calendários vigentes.

Todas essas mudanças ocorridas no sistema de medidas vigente na época, as causas que conduziram à adoção de um novo sistema, a existência de outros sistemas além do que é adotado no Brasil (sistema métrico), podem convergir para outros temas e suas referidas consequências, como exemplifica o trabalho com as séries numéricas e a preferência pelos aos múltiplos de 10 .

\footnotetext{
${ }^{3}$ Em 1898, A tradução das Lettres em castelhano divulgou todas as unidades de medida utilizadas até o período que antecedeu ao sistema métrico decimal. O sistema métrico foi instituído na França pela lei de 7 de abril de 1795. Na Espanha eram usadas as léguas espanholas equivalentes a 8000 varas castelhanas ou 24000 pés. Passou a ser obrigatório neste país em de 19 de julho de 1849. (PÉREZ, 1990).
} 
Abaixo, listo alguns conteúdos matemáticos identificados e outros que podem emergir a partir do uso didático das Cartas I e II na Educação Básica:

1. Unidades de medida de comprimento não usuais (pé, polegada e milha)

2. Relações de equivalência entres as medidas de comprimento;

3. Sistema métrico decimal;

4. Outros sistemas de medida (peso, volume, área);

5. Unidades de medidas não usuais (peso, volume, área);

6. Conversão de unidades de medidas;

7. Medidas de tempo;

8. Cálculo de distâncias;

9. Relação entre tempo e distância;

10. Grandezas direta e inversamente proporcionais;

11. Proporcionalidade;

12. Dobro e triplo de números naturais;

13. Frações $\left(\frac{1}{2} ; \frac{1}{4}\right.$ e $\left.\frac{1}{8}\right)$

14. Diâmetro de figuras planas e espaciais;

Assinalamos que os conteúdos listados nestas e nestas cartas não estão esgotados e, ainda permitem no mínimo algumas dezenas de possibilidades de serem trabalhadas por práticas escolares que podem recorrer ao uso da História da Matemática na sala de aula para contemplar o exercício da transversalidade entre esta disciplina e outras áreas como as ciências naturais, a física, a geografia, a história, a língua portuguesa, línguas estrangeiras, ensino de artes e música.

\section{Considerações finais}

O talento de Euler como um importante matemático e físico do século XVIII já foi aspecto reconhecidamente destacado ao longo da História.

Porém, segundo Klyve (2011) sobre a função docente de Euler, que alerta desconsiderar, neste caso, a complexidade que envolve a temática sobre formação de professores, aponta que Euler cultivou as três atitudes essenciais para alcançar seus objetivos como um bom professor. O matemático atraiu e manteve o interesse de seus leitores; apresentou os conceitos a partir de uma escala de dificuldade, relacionando as 
ideias mais simples até atingir as mais difíceis e elaboradas e, finalmente foi suas explicações eram precisas sem exaustivos detalhes desnecessários.

Euler, a julgar pelas qualidades consideradas por Klyve (2011) supera com vantagens as expectativas para ser considerado um professor dedicado, ao revelar uma leitura divertida, envolvente, com temas desenvolvidos de forma atraente que remetem à imensidão do universo.

Outro aspecto relevante sobre o uso das Lettres de Euler, diz respeito ao modo transversal com que as sequências de ideias são conduzidas dentro dos limites de cada correspondência e nas subsequentes que compõem a obra. $\mathrm{O}$ arrojado entrelaçamento é amarrado de tal forma que os conteúdos vão surgindo dos mais simples até os mais complexos, até desembocarem, se necessário for em outras áreas do conhecimento, que podem ser discutidas na mesma carta ou servirem de fio condutor para o tema da próxima correspondência.

O desafio de desancorar um texto do século XVIII e margeá-lo no século XXI é imenso. Expor o diálogo reservado entre Euler e a princesa alemã às classes de matemática da Educação Básica é desafiador.

Apesar de haver três séculos nos separando da escrita da obra original, é bem verdade que existe um ponto de convergência que nos aproxima dos propósitos de Euler para este seu trabalho, que é ato de ensinar. Uma ação definida aqui como atemporal e, que poderá contribuir na travessia do tempo e do espaço, a fim de que possamos propor uma leitura atualizada de Lettres à une Princesse d'Allemagne sur divers sujets de physique et de philosophie e que se descortinem novas possibilidades de se reescrever outras metodologias de ensino para as aulas de matemática.

\section{Referências}

BRASIL. Secretaria de Educação Fundamental. Parâmetros Curriculares Nacionais: matemática. Brasília, DF, 1998.

BRASIL. Conselho Nacional de Educação (CNE). Parecer n. 15, de 1 de junho de 1998. Diretrizes Curriculares Nacionais para o Ensino Médio. Brasília, DF, 1998b.

FELLMANN, E. A. Leonhard Euler. Trad. Erika Gautschi e Walter Gautschi. Basel, Suíça: Birkhäuser Verlag, 2007. 
JAHNKE, H. N. et al. The use of original sources in the mathematics classroom. In: FAUVEL, J; VAN MAANEN, J. (Org.).History in Mathematics Education: The ICMI Study. Dordrecht: Kluwer Academic Publishers, 2002. Vol 6, Cap. 5. p. 291-328.

MENDES, I. A. Ensino de matemática por atividades: uma aliança entre o construtivismo e a história. 283. Tese (Doutorado em Educação) - Universidade Federal do Rio Grande do Norte, Natal, 2001, $207 \mathrm{f}$.

MENDES, I. A. Investigação histórica no ensino de matemática. Rio de Janeiro: Editora Ciência Moderna Ltda, 2009.

MENDES, I. A.; FOSSA, J. A. e VALDÉS, J. E. N. A História como um agente de cognição na Educação Matemática. Porto Alegre: Sulinas, 2006.

MENDES, I. A; FARIAS, C. A (Orgs). Práticas socioculturais e educação matemática. São Paulo: Editora Livraria da Física, 2014. (Coleção Contextos da Ciência).

MiguEL, A; BRITO, A de J; CARVALHO, D. L de; MENDES, I. A. História da Matemática em Atividades Didáticas. São Paulo: Ed. Livraria da Física, 2009b. (Coleção Contextos da Ciência).

PEREIRA, D. E. Correspondências científicas como uma relação didática entre história e ensino de matemática: o exemplo das cartas de Euler a uma princesa da Alemanha. Tese (Doutorado). Universidade Federal do Rio Grande do Norte. Centro de Educação. Programa de Pós-Graduação em Educação. Natal/RN, 2014, 276 f.

PÉREZ, C. M. Prefácio do livro Cartas a una princesa de Alemania sobre diversos temas de física y filosofia de Leonhard Euler. Tradução de Carlos Mínguez Pérez. Zaragoza: Universidad, Prensas Universitarias, 1990. P. 51 - 69

TODOS PELA EDUCAÇÃO. De olho nas metas 2013-14. Sexto relatório de monitoramento das 5 Metas do Todos pela Educação. São Paulo, 2015. Disponível em < http: www.todospelaeducacao.org.br/5. Acesso em 01 de julho de 2015. 